\title{
High time to invest in biodiversity
}

\author{
The delay in final negotiations on the global post-2020 biodiversity framework is providing time for additional \\ scientific evidence, and for strengthening ideas around natural capital.
}

n our January 2020 editorial, we were looking forward to contributing to a 'super year of biodiversity'. Like many plans for last year, the fifteenth meeting of the Conference of the Parties to the Convention on Biological Diversity (CBD), at which global commitments for a post2020 biodiversity framework were to be made, is still on hold, while nations watch to see when in-person negotiations may again be feasible. Biodiversity loss is continuing, even accelerating ${ }^{1}$, with every passing day, making delays in adopting renewed pledges regrettable. But there are glimmers of hope that the intervening months, and the pandemic backdrop, are providing not only time to refine the scientific evidence, but perhaps also a political environment that is more receptive to the need for transformative change.

Our journal's commitment to provide a forum for stakeholders to engage with each other as they hone the final framework continues. Together with Nature Sustainability, we have assembled a Collection of recent research and opinion articles with direct relevance to the current draft post-2020 CBD framework ${ }^{2}$. They encompass work on the three main CBD pillars of preserving species, ecosystems and genetic diversity, as well as on the broader intersection of biodiversity conservation with human society, and the interdependence of biodiversity and climate policy. We will add papers to the Collection over the year.

Conservation scientists rightly insist that the post-2020 biodiversity goals must be ambitious $^{3}$. Yet it is increasingly recognized that bold, global targets are only a first step, and can lack meaning or even lead to perversely negative outcomes, if they are not accompanied by adequate spending and scientific infrastructure for national and local-level implementation and monitoring. A Perspective by $\mathrm{Xu}$ et al. ${ }^{4}$ provides evidence for why the previous framework - the 2010 Aichi Targets - were resoundingly not met. They show that most parties did not set effective national targets in accordance with the Aichi agenda, and that insufficient investments, knowledge and accountability hampered implementation attempts. They call for a substantial increase in finance for biodiversity conservation, and systems for monitoring compliance and accountability.

Finance is also the focus of an Article from Seidl et al. ${ }^{5}$, reporting on the results of the Biodiversity Finance Initiative (BIOFIN) project tracking national-level biodiversity investments. They find that public spending on biodiversity is, across the board, increasing, but that wealthier countries - by the traditional gross domestic product (GDP) measure of 'wealth' - spend proportionally less on biodiversity than lower-GDP nations. This must change. Higher-GDP nations are increasingly accountable for 'offshore' biodiversity loss through trade ${ }^{6}$, and must pay for, and reduce, these remote impacts.

A need for more equitable spending to conserve and restore nature was one of the key recommendations of the independent Dasgupta Review on the Economics of Biodiversity, led by economist Partha Dasgupta and commissioned by the UK Treasury, published on 2 February $2021^{7}$. The Review emphasizes that reversing the trend of biodiversity loss now will be less costly than delay. It identifies deep-rooted institutional failure as the heart of the problem of biodiversity loss, and calls for a fundamental change in our definition of wealth: away from the mindset of unsustainable growth characterized by GDP measures, and towards an inclusive measure of wealth that recognizes natural assets. It is sad that conservation scientist Georgina Mace did not live to see this very prominent integration of many of her ideas around natural capital ${ }^{8}$.

This sober and evidenced recognition of the need for transformed ideas of wealth and progress is welcome, but should also be accompanied by a pragmatic acceptance that rich nations - by current definitions should pay more, immediately, to conserve and preserve nature. Implementing both transformative change and rapid spending on biodiversity seems difficult in the midst of the COVID-19 pandemic, with widespread individual economic hardship in many 'wealthy' nations. It will require extreme political will not to fall back on retrograde economic fixes.

But in some regards, the pandemic may have brought biodiversity negotiations some luck. Science and expert advice are being accorded more respect in many circles now than a year or two ago, not least in the United States under the new Biden-Harris administration. The superior economic and social outcomes in countries that have followed evidence-based pandemic responses should give enhanced credence to science-based messaging in general, including that greatly strengthened conservation and climate action are economically essential for all nations now, let alone in the longer-term future. Perhaps a US CBD delegation under President Biden will be more empowered and collaborative than might have been possible under previous delegations - and finally join almost every other nation in ratifying the agreement. And it can be hoped that all nations will incorporate the mounting evidence that biodiversity loss and land-use change contribute to zoonotic disease emergence into the urgency of the negotiations.

In the background, the remaining months will give scientists and advisers additional time for research, discussion and coalescence of ideas. We look forward to further contributing to that process.

Published online: 4 March 2021

https://doi.org/10.1038/s41559-021-01416-0

\footnotetext{
References

1. Silva Junior, C. H. L. et al. Nat. Ecol. Evol. 5, 144-145 (2021)

2. Updated Zero Draft of the Post-2020 Global Biodiversity

Framework (Convention on Biological Diversity, 2020); http:// go.nature.com $/ 3 \mathrm{j}$ WOnsr

3. Díaz, S. et al. Science 370, 411-413 (2020).

4. Xu, X. et al. Nat. Ecol. Evol. https://doi.org/10.1038/s41559-02001375-y (2021).

5. Seidl, A., Mulungu, K., Arlaud, M., van den Heuvel, O. \& Riva, M. Nat. Ecol. Evol. https://doi.org/10.1038/s41559-020-01372-1 (2021).

6. Marques, A. et al. Nat. Ecol. Evol. 3, 628-637 (2019).

7. Dasgupta, P. The Economics of Biodiversity: The Dasgupta Review (HM Treasury, 2021); http://go.nature.com/2OM5hhO

8. Bateman, I. J. \& Mace, G. M. Nat. Sustain. 3, 776-783 (2020).
} 